\title{
PIGLET SIGN OF CENTRAL PONTINE MYELINOLYSIS
}

Sonjjay Pande ${ }^{1}$, Tarun Nagpal2 ${ }^{2}$ Avadhesh P. S. Kushwah³ ${ }^{3}$ Arun Sharma ${ }^{4}$

\section{HOW TO CITE THIS ARTICLE:}

Sonjjay Pande, Tarun Nagpal, Avadhesh P. S. Kushwah, Arun Sharma. "Piglet Sign of Central Pontine Myelinolysis". Journal of Evolution of Medical and Dental Sciences 2014; Vol. 3, Issue 19, May 12;

Page: 5207-5209, DOI: 10.14260/jemds/2014/2575

ABSTRACT: A 35 year chronic alcoholic old man, was admitted with altered sensorium since last 3 days. His MRI Brain done on Day 3 of admission revealed Hyperintense signal change in pons with partial sparing of the tegmentum, ventrolateral pons and corticospinal tracts on FLAIR and T2 weighted images suggestive of central pontine myelinolysis. The T2W axial images resembled the face of a pig with the temporal lobes representing ears, the carotid arteries the eyes, the abnormal pontine signal representing snout and the fourth ventricle the mouth. Recognition of this pattern -the piglet sign may aid in the differential diagnosis of pontine lesions.

KEYWORDS: 1) Piglet sign, 2) Central pontine myelinolysis, 3) MRI

INTRODUCTION: A 35 year old man was admitted with altered sensorium since last 3 days. He was a chronic alcoholic. His examination showed equal reactive pupils. He had Glasgow Coma Scale of 8(E2M3V3). Bilateral plantar reflexes were extensor.

His serum sodium initially was $103 \mathrm{~m} \mathrm{Eq} / \mathrm{l}$ and had been corrected to $123 \mathrm{mEq} / \mathrm{l}$ over a day. His MRI Brain done on Day 3 of admission revealed the following interesting finding: Hyperintense signal change in pons with partial sparing of the tegmentum, ventrolateral pons and corticospinal tracts on FLAIR (Fig. 1) and T2 (Fig. 2) weighted images suggestive of central pontine myelinolysis. The axial images resembled the face of a pig (fig. 3) with the temporal lobes representing ears, the carotid arteries the eyes, the abnormal pontine signal representing snout and the fourth ventricle the mouth. Recognition of this pattern -the piglet sign may aid in the differential diagnosis of pontine lesions.

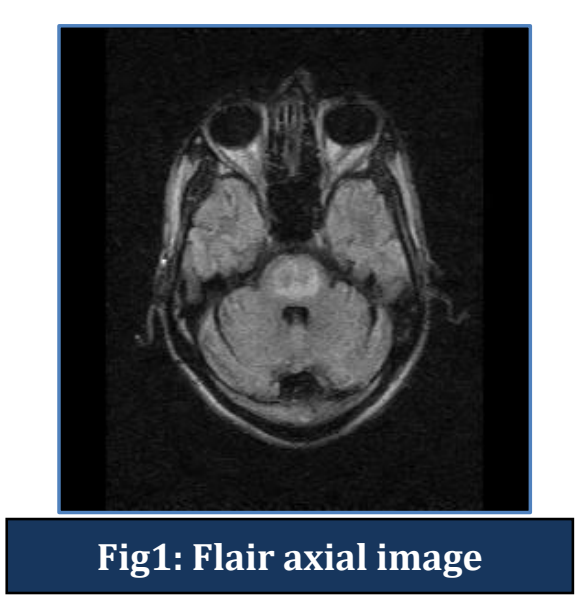




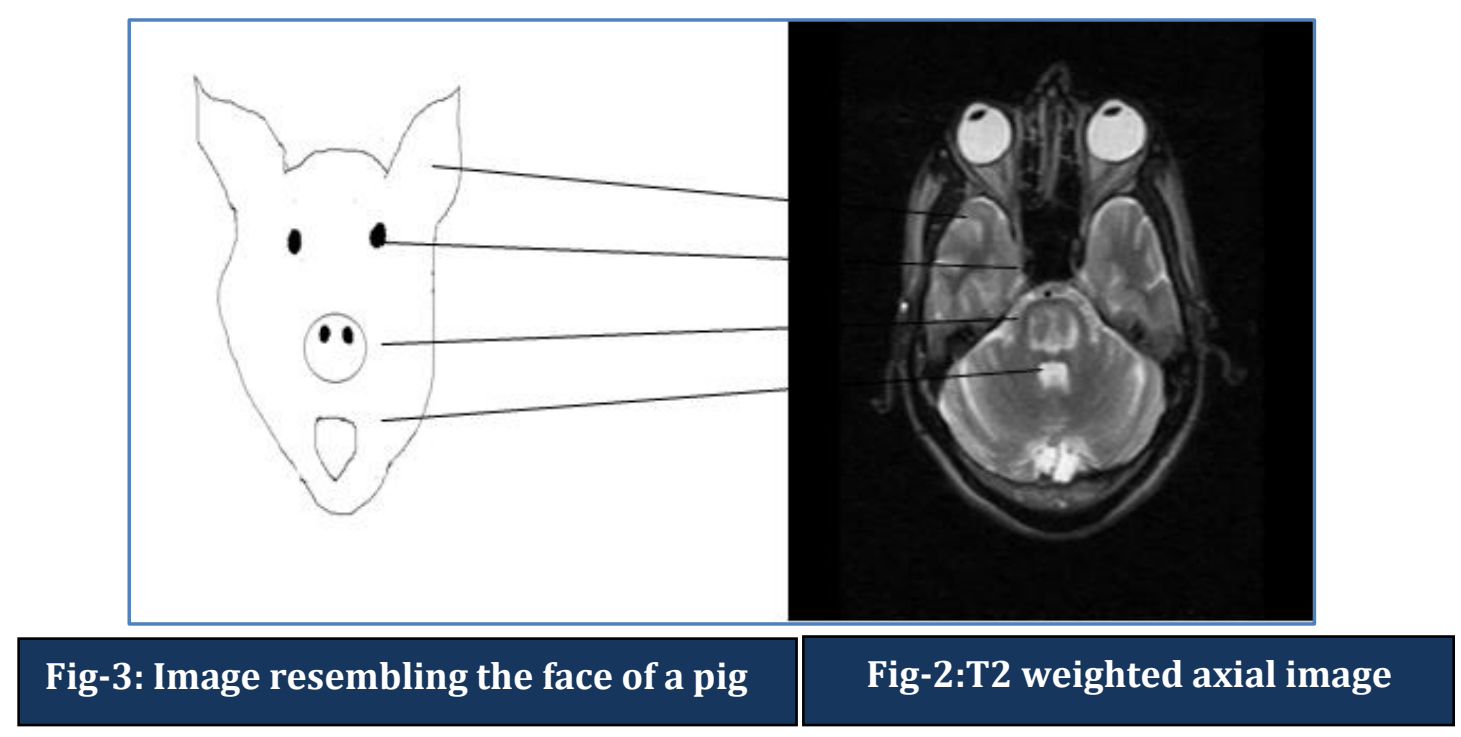

DISCUSSION: It is suggested that the rise in serum sodium exerts an osmotic endothelial injury leading to the local release of myelinotoxic factors derived from more vascular grey matter. ${ }^{1}$ The absence of myelinolysis in pure white matter tracts such as the internal capsule supports this view. Autopsy studies in early CPM have shown altered lipid: protein ratios, little inflammatory reaction, relative sparing of the axons, and oedema. ${ }^{2}$

This latter element accounts for the hypointense signals seen on T1 MRI sequences and the hyperintense signals seen on T2 sequences early in the course of CPM. Extra-pontine myelinolysis may also be a feature, particularly involving the thalami and the basal ganglia, but there is a particular predilection for the pons. These areas all have a relatively high grey/white matter interface.

The typical location of CPM is center of dorsal basis pontis and displays a round or oval shape on axial MR sections in acute CPM or a triangular shape in chronic or subacute CPM. ${ }^{3}$ Larger lesions extend laterally while sparing the corticospinal and corticobulbar tracts. Coalescence of areas of demyelination gives the appearance of a piglet. ${ }^{4}$

\section{REFERENCES:}

1. Norenberg MD, Leslie KO, Robertson AS. Association between rise in serum sodium and central pontine myelinolysis. Ann Neurol 1982; 11: 128-35.

2. Gocht A, Colmant HJ. Central pontine and extrapontine myelinolysis: a report of 58 cases. Clin Neuropathol 1987; 6:262-7.

3. Chua GC, Sitoh YY, Lim CC, Chua HC, Ng PY. MRI findings in osmotic myelinolysis. Clin Radiol 2002; 57:800-6.

4. Judith Wagner, Stefanie-Muller Schunk, Christoph Schankin. The Piglet Sign: MRI findings in Central Pontine Myelinolysis. Clin Neurorad 2008; 3:191. 


\section{CASE REPORT}

\section{AUTHORS:}

1. Sonjjay Pande

2. Tarun Nagpal

3. Avadhesh P. S. Kushwah

4. Arun Sharma

\section{PARTICULARS OF CONTRIBUTORS:}

1. Associate Professor, Department of Radiodiagnosis, NSCB Medical College, Jabalpur, (M. P.), India.

2. Consultant, Department of Neurophysician, Aditya Hospital, Napier Town, Jabalpur, (M. P.), India.

3. Assistant Professor, Department of Radiodiagnosis, NSCB Medical College, Jabalpur, (M. P.), India.
4. Professor, Department of Radiodiagnosis, NSCB Medical College, Jabalpur, (M. P.), India.

\section{NAME ADDRESS EMAIL ID OF THE CORRESPONDING AUTHOR:}

Dr. Sonjjay Pande,

Vatika Duplex,

\#65, Napier Town,

Jabalpur - 482001.

E-mail: drsonjjaypande1@gmail.com

Date of Submission: 10/04/2014.

Date of Peer Review: 11/04/2014.

Date of Acceptance: 18/04/2014.

Date of Publishing: 09/05/2014. 